\title{
Predicting School Readiness for Low-Income Children With Disability Risks Identified Early
}

\author{
HYUN-JOO JEON \\ The University of Alabama \\ CARLA A. PETERSON \\ Iowa State University
}

\section{SHAVAUN WALL}

The Catholic University of America

\section{JUDITH J. CARTA \\ University of Kansas}

\section{GAYLE LUZE}

Iowa State University

\section{ELAINE M. ESHBAUGH}

University of Northern Iowa

\section{MARK SWANSON}

Centers for Disease Control and Prevention

AвSTRACT: This study examined school readiness at kindergarten entry for low-income children whose disability indicators were identified before age 3. Data were collected as part of the Early Head Start Research and Evaluation Longitudinal Follow-Up study. Children who had suspected developmental delays and did not receive Part $C$ services had lower preacademic skill scores at kindergarten entry than those who had no disability indicators. In contrast, the preacademic skills at age 5 of children who received Part $C$ services did not differ from those who had no disability indicators. A large proportion of children who had suspected developmental delays and did not receive Part $C$ services by age 3 received Part $B$ services later. Results highlight the importance of early intervention for low-income children who have suspected developmental delays to enhance their school readiness skills.

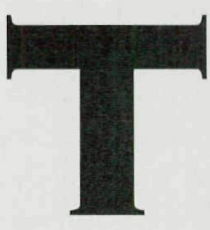

he development of cognitive, language, and social skills in the first years of life provides an essential foundation for learning more advanced skills throughout the school years. The National Education Goals Panel (1998) aspired to have all children start school ready to learn; this goal has spurred attention to early childhood services. School readiness is generally defined as academic and social 
competencies that help children have successful learning experiences when they enter school (Mashburn \& Pianta, 2006; Rimm-Kaufman \& Pianta, 2000; Snow, 2006). Children's academic and social competencies at kindergarten entry are important predictors of success throughout school. Children who enter school not ready to learn struggle with academic difficulties and manifest social and behavior problems in later school years (Duncan et al., 2007; Ladd, 2006).

\section{Children's academic and social competencies at kindergarten entry are important predictors of success throughout school.}

Children from low-income families are often significantly less ready for school than their more advantaged peers. At kindergarten entry, the average cognitive scores of children from families with the lowest socioeconomic status are $60 \%$ lower than the average scores of those from families with the highest socioeconomic status (Lee \& Burkam, 2002). This socioeconomic gap in development is evident early. The effects of poverty on children's development appear at about age 2 and are pronounced by age 3 (Brooks-Gunn \& Duncan, 1997; Duncan \& Brooks-Gunn, 2000). The early developmental gaps associated with poverty persist even into high school (Duncan, Yeung, Brooks-Gunn, \& Smith, 1998). Moreover, the adverse effects of poverty are often more extreme when poverty is experienced during earlier compared to later childhood periods (Duncan et al., 1998; Votruba-Drzal, 2006).

In addition, children from low-income families are more likely to have developmental risks and disabilities that limit their school readiness than those from middle-income families (BrooksGunn \& Duncan, 1997; Fujiura \& Yamaki, 2000; Scarborough, Spiker, Mallik, \& Hebbeler, 2004). This finding was evident in the sample of children living in poverty who participated in the Early Head Start Research and Evaluation (EHSRE) project. These children were more than twice as likely to receive Part $\mathrm{C}$ early intervention services before age 3 (4.7\%; Peterson et al., 2004) than those in the general U.S. population in 2000
(1.8\%; National Early Childhood Technical Assistance Center, 2007); many more children were identified as having developmental risks that likely would have made them eligible for Part C services though they were not enrolled (Peterson et al., 2004).

Previous research regarding the development of children with developmental risks or disabilities generally has been restricted to studies of children with single conditions. Recent studies of developmental status for children with disabilities have focused on children with specific conditions, such as Down syndrome (Carr, 2005), traumatic brain injury (Hammond, Hart, Bushnik, Corrigan, \& Sasser, 2004), low birth weight (Dieterich, Hebert, Landry, Swank, \& Smith, 2004), or neuromuscular disease (Lomax-Bream et al., 2007). Although studies of children with specific diagnosed conditions are important, children in poverty are at greater risk for experiencing general developmental delays, as well as a variety of health-related conditions. Relatively little, however, is known about the school readiness of children whose development may be compromised not only by poverty but also by developmental disabilities or biological risks. The purposes of the current study are twofold:

- To compare school readiness at kindergarten entry of low-income children who were identified as having suspected developmental delays or biological risks before age 3 but received no Part $\mathrm{C}$ intervention with the readiness of children who received Part $\mathrm{C}$ services and those who had no disability.

- To examine the contribution of Part $\mathrm{C}$ and Part B interventions to children's school readiness.

\section{PART C AND B SERVICES}

The Individuals With Disabilities Education Improvement Act (IDEA) mandates Part $\mathrm{C}$ programs for infants and toddlers and Part B programs for preschoolers. Part $\mathrm{C}$ programs are designed to serve families of children with established developmental delays and those at risk for developmental delays. IDEA allows each state to set eligibility criteria; as a result, states vary in 
determining how children will qualify for Part C services. Moreover, many low-income children may have developmental delays or other developmental risks yet do not receive Part $\mathrm{C}$ services because they are never identified or because their parents choose not to receive those services (Peterson et al., 2004). Few researchers have examined developmental outcomes of children who received Part C services (Carlson et al., 2008). Thus, little is known regarding comparisons of school readiness among children who did and did not receive Part $\mathrm{C}$ services.

Many educators have emphasized the importance of early intervention for children with developmental risks and disabilities. In the National Pre-Elementary Education Longitudinal Study (PEELS), children who received Part B early childhood special education services were followed until they entered elementary school, where a significant improvement in their literacy and cognitive standardized scores were noted among children with developmental delays, learning disabilities, or speech/language impairments (Carlson et al., 2008). The PEELS study, however, did not compare the outcomes of children served to those who did not receive Part C or Part $\mathrm{B}$ services. Comparing the school readiness of children who received Part C or Part B services to that of children who were identified as having disability indicators before age 3 but who did not receive Part C or Part B intervention services could prove helpful in the design and delivery of early intervention and early childhood special education services for low-income children.

\section{CHILDREN WITH}

\section{DEVELOPMENTAL DELAYS}

The percentage of children with developmental delays who receive intervention services increases as children get older. In the National Early Intervention Longitudinal Study (NEILS), only 10\% of children receiving Part $\mathrm{C}$ early intervention services before age 3 (excluding those with a physical growth abnormality) were identified as having a developmental delay so as to meet service requirements (Scarborough et al., 2004). In the PEELS, $26 \%$ of children receiving Part B services were identified as having a developmental delay (Carl- son et al., 2008). Some children with developmental delays may not be referred for Part $C$ services. In addition, assessment measures for infants and toddlers may not be sensitive enough to detect developmental delays, and eligibility criteria for Part B and Part C are different. Scarborough et al. found that most children identified as eligible for services due to having a developmental delay received Part $\mathrm{C}$ services later than those in any other eligibility categories.

Children with developmental delays present great variability in their initial evaluation results across developmental domains, as well as in later developmental outcomes (Aylward, 2002). Only two studies, however, have examined the kindergarten readiness of children whose developmental delays were identified early in life (Carlson et al., 2008; Shevell, Majnemer, Platt, Webster, \& Birnbaum, 2005). The PEELS followed children who received Part B (preschool special education) services. Results showed significant gains in standardized preacademic, language, and social skills scores over time for children with developmental delays even though their standardized school readiness scores were still lower than those of children without delays (Carlson et al., 2008).

To date, there is no information about the developmental status or school readiness of lowincome children who are identified as having developmental delays but do not receive Part C services. Comparing the developmental status and school readiness of children who have developmental delays early in life and yet do not receive early intervention services to those of children who have received Part C or Part B services could provide information about the influence of intervention for children in poverty who have developmental delays before age 3 .

\section{CHILDREN WITH BIOLOGICAL RISKS}

According to eligibility categories in Part $\mathrm{C}$ of IDEA, biological risks are chronic health conditions that have a relatively low association with developmental problems (Shackelford, 2006). In the EHSRE sample, children who had anemia, asthma, diabetes, ear infections, epilepsy, a heart defect, lead exposure, low weight problems, or 
respiratory problems were identified as having biological risks (Peterson et al., 2004). Several researchers (Dieterich et al., 2004; Landry, Smith, \& Swank, 2006) have found associations among children's development, low birth weight, and environmental/psychological factors (e.g., poverty and parenting). Steen and Campbell (2008) reviewed studies on the cognitive effect of children's illnesses that are not directly associated with brain function but have the potential to influence development. They found that young children with diabetes or severe diarrhea had lower school achievement and cognitive functioning in later life and those with high lead exposure had an increased risk of school failure and behavioral problems compared to those without these biological risks. Little work has been done, however, to examine school readiness for children who face various mild biological risks but are not diagnosed with a developmental delay in early life. It would be beneficial, therefore, to examine the later developmental status and school readiness of children who face biological risks but do not receive Part $\mathrm{C}$ services to determine whether these children need additional intervention or support for their development.

\section{OTHER FACTORS RELATED \\ TO SCHOOL READINESS}

Children's development and school readiness are related to their home and early care and education environments. Researchers have found that maternal education (Bracken \& Fischel, 2008) and depression (Chapin \& Altenhofen, 2010), home environments (Chazan-Cohen et al., 2009; Krishnakumar \& Black, 2002), home language (Lee \& Burkam, 2002), family income (Lee, 2005; Lee \& Burkam, 2002), minority status (Panter \& Bracken, 2009), and early care and education experiences (Love et al., 2003; National Institute of Child Health and Human Development Early Child Care Research Network, 2002) predict children's development and school readiness. In the current study, these variables are considered as possible covariates when examining children's school readiness.

\section{PURPOSES OF THE}

CURRENT STUDY

The current study aimed to predict the school readiness skills of children from low-income families identified as having a disability indicator before age 3 , based on direct child assessments, parent interviews, and/or early care and education provider reports. The study examined school readiness outcomes for five groups of children based on their disability indicators identified before age 3: children who received Part C, children with a suspected developmental delay, children with a biological risk, children with a suspected developmental delay and a biological risk, and children with no identified disability indicator. We addressed the following research questions about these children:

- Are there differences in school readiness skills for children with and without disability indicators after controlling for relevant covariates (e.g., child and family characteristics and experiences) and Part B service receipt status?

- Are there differences in school readiness skills for children who did and did not receive Part B services after controlling for disability indicators identified before age 3 and relevant covariates?

\section{ET HO D}

The current study was conducted as secondary data analyses using the data from the EHSRE and EHSRE Longitudinal Follow-Up studies. Lowincome families $(N=3,001)$ located in 17 communities in the original EHSRE Project were eligible for Early Head Start (EHS) and were randomly assigned to receive EHS services (program group) or to a control condition in which the families were free to participate in any community services except EHS. Each family had a child who was less than 1 year of age at the time of EHSRE enrollment between 1996 and 1998, and the target child was followed from EHSRE enrollment until the child was 3 years of age (Administration for Children and Families, 2002). The EHSRE Longitudinal Follow-Up study was designed to investigate the long-term effects of EHS and other program experiences on low- 
income children's development and family wellbeing measured at the time the child was ageeligible to enter kindergarten (Love et al., 2011), and included data collected from children, their families, and early care and education teachers. For more details about the EHSRE and EHSRE Longitudinal Follow-Up study methodology, see the final project report from the Administration for Children and Families.

\section{P A RTICI P A N T S}

The current study included children $(N=2,183)$ who participated in the EHSRE Longitudinal Follow-Up study. The children's EHS program status was not related directly to research questions in the current study nor to the children's disability indicators or school readiness scores. Thus, children from both the EHS and control groups were combined in the current analyses.

Children were divided into five disability categories based on indicators that reflected conceptualization of disability and developmental risk outlined in IDEA and that were collected for the EHSRE study through parents' and EHS staff members' reports and direct child assessment information before age 3 (Peterson et al., 2004). Children who received Part $\mathrm{C}$ services were identified based on reports by their parents and EHS program staff. Children were identified as having a "suspected developmental delay" based on low scores on direct child assessments (e.g., Bayley MDI score $<1.5 S D$ below the mean) or parent reports that a health professional had reported suspected developmental delay. Children were categorized as having a biological risk if their parents reported they had one or more chronic health conditions that have a fairly low association with developmental problems (e.g., diabetes, anemia, congenital heart disease). The five disability categories were mutually exclusive for the purposes of this current study. The numbers of children in each category follow: (a) children who received Part C services ( $n=129)$, (b) children identified as having a suspected developmental delay only $(n=287)$, (c) children identified as having a biological risk only $(n=741)$, (d) children identified as having both a suspected developmental delay and a biological risk $(n=395)$, and (e) children who did not have any identified disability indicator by age $3(n=631)$.

\section{MEASURES}

Trained examiners directly assessed children's preacademic skills and approaches toward learning. Parents responded to interview questions related to their own health and well-being, their interactions and daily activities with their children, and their children's social behaviors. All children's school readiness measures were collected during the spring or summer before the children were age-eligible for kindergarten entry.

\section{PREACADEMIC SKILLS}

Receptive Language. The Peabody Picture Vocabulary Test, 3rd edition (PPVT-III; Dunn \& Dunn, 1997) was used as a measure of children's receptive vocabulary. The PPVT-III score relates to other measures of language, literacy, and academic achievement (Dunn \& Dunn, 1997). The reported Cronbach's alpha coefficient for all test items ranged from .92 to .98 , and test-retest reliability is reported as ranging from .85 to .90 . Cronbach's alpha coefficient of PPVT-III for the EHSRE Longitudinal Follow-Up study sample was .96 (Love et al., 2011).

Story and Print Concepts. The Story and Print Concepts task is designed to measure children's knowledge about how print works and their story comprehension. The measure was adapted for the Head Start Family and Child Experiences Survey (FACES) from the original assessment developed by Mason and Stewart (1989). The examiner asks the child questions while showing a story book, Goodnight Moon (Brown, 1947). This scale consists of a total of 9 items. The first 8 items are scored yes (1) or no (0); for example, "Show me the front of the book." The last item is rated from 0 to 3 based on the number of things that the child answers to a question, "Can you tell me some other things we said 'goodnight' to?" The highest possible score is 11. Items are organized into two subscales: Book Knowledge and Book Comprehension. Spearman-Brown test-retest reliability was .91 (Roberts \& Neal, 2004). Children's scores on the Story and Print Concepts at the end of the Head Start year predicted their 
General Knowledge and Book Knowledge scores on the cognitive assessment used in the Early Childhood Longitudinal Study of a kindergarten cohort (Sorongon, Kim, \& Zill, n.d.).

Letter-Word Identification. The Letter-Word Identification Subtest of the Woodcock-Johnson Psycho-Educational Test Battery-Revised (W-J; Woodcock \& Johnson, 1990) was used as a direct measure of children's ability to identify letters and words. The Woodcock-Muñoz-Revised Identificación de Letras y Palabras (Woodcock \& Munoz-Sandoval, 1996) was used for children whose primary language was Spanish. In this study, the English and Spanish version test scores were combined because these two versions of the tests are comparable. Cronbach's alpha coefficient in the EHSRE Longitudinal Follow-Up study was reported as 84 (Love et al., 2011).

Applied Problems. The Applied Problems Subtest of the Woodcock-Johnson Psycho-Educational Test Battery-Revised (W-J; Woodcock \& Johnson, 1990) was used as a direct measure of children's ability to analyze and solve math problems. The Woodcock-Muñoz-Revised Problemas Aplicados (Woodcock \& Munoz-Sandoval, 1996) was used for children whose primary language was Spanish. In this study, the English- and Spanish-version test scores were combined because these two versions of the tests are comparable. The standardized scores were calculated based on child's date of birth. Cronbach's alpha coefficient in the EHSRE Longitudinal Follow-Up study was reported as .85 (Love et al., 2011).

\section{SOCIAL-EMOTIONAL SKILLS}

Leiter-R Examiner Rating Scale (Leiter-R; Roid \& Miller, 1997). The Leiter-R Examiner Rating Scale, originally used in conjunction with the administration of the Leiter International Performance Scale-Revised test, measures children's affect and behavior during testing. The ratings were completed based on behavioral observations of the child throughout the entire child assessment in the current study. Observers used the 4-point Leiter-R Examiner Rating Scale to rate children's attention, organization and impulse control, activity level, sociability, energy and feelings, anxiety, and sensory reactivity. In the EHSRE Longitudinal Follow-Up study, two com- posites scores were calculated: Cognitive Social and Emotional Regulation. The Cognitive Social composite score refers to a constellation of motivational, interpersonal, and test-performance skills related to school success. The Emotional Regulation composite score refers to effective emotional self-regulatory aspects of performance in challenging tasks, which are prerequisites for academic success (Love et al., 2011). Standardized scores were calculated for these two composite scores. Cronbach's alpha coefficients of the Cognitive Social and Emotional Regulation composite were .93 and .96, respectively (Love et al., 2011).

Social Skills and Positive Approaches to Learning (SSPAL). Parents rated children's SSPAL using the modified Social Skills Rating System (SSRS; Gresham \& Elliott, 1990) and the Entwisle Scale of Personal Maturity (Entwisle, Alexander, Pallas, \& Cadigan, 1987) to capture children's positive social interaction skills, as well as their behavioral dispositions toward learning (Love et al., 2011). The SSPAL scale consists of 7 items rated on a 3 -point Likert scale $(0=$ not true, $1=$ somewhat/sometimes true, and $2=$ very true/often true). Summative scores were calculated, with higher scores indicating more positive social skills and approaches to learning. The highest possible score was 14 . In the current study, Cronbach's alpha coefficient was .64 (Love et al., 2011).

Aggressive Behavior Problems. The Child Behavior Checklist (Achenbach \& Rescorla, 2000) is a 99-item behavioral checklist, used to measure the behavioral, emotional, and social functioning of children from $1 \frac{1}{2}$ to 5 years old. Parents rate their children's behaviors using a 3 -point scale $(0=$ not true, 1 = somewhat/sometimes true, and $2=$ very true/often true). The EHSRE Longitudinal Follow-Up study team selected 19 items of the Aggressive Behavior subscale to capture the children's aggressive behavior (Love et al., 2011). The highest possible score on Aggressive Behavior is 38 . Cronbach's alpha coefficient of the Aggressive Behavior scores was 89 in the EHSRE Longitudinal Follow-Up study (Love et al., 2011).

\section{OTHER VARIABLES}

Several child and family characteristic variables were used as control variables in the current study. 
In this examination, child gender, age, ethnicity, family income, and public assistance usage were included. Types of early care and education that children experienced after the age of 36 months were also used (e.g., whether they were enrolled in a Head Start program, a center-based child care program, an informal care setting, or the EHS program). Maternal education and depression symptoms and home environment were also examined in the current data analyses.

Caregiver Depression. The Center for Epidemiological Studies Depression Scale (CES-D; Radloff, 1977) is a 20-item, self-administered measure of cognitive, affective, and behavioral depressive symptoms. In the EHSRE Longitudinal Follow-Up, 12 items were selected from the original scale to assess parent's depressive symptoms. Summative scores (ranging from 0 to 36 ) were calculated with higher scores indicating more depressive symptoms. Cronbach's alpha coefficient of the CES-D scores was .88 in the EHSRE Longitudinal Follow-Up study (Love et al., 2011).

Quality of Home Environment. The Home Observation for Measurement of the Environment Inventory (HOME; Caldwell \& Bradley, 2003) was used to assess the warmth in the child's home, as well as the stimulating quality of the home learning environment. A modified version consisting of 20 items of the original 72 was used to assess the quality of the home environment of young children through observation and direct parent interview in the current study. Cronbach's alpha coefficient of the original HOME measure was .84 ranging from .49 to .78 for different subscales. One of the HOME authors, however, argues that traditional psychometric properties are not helpful for indicators measuring all aspects of home environments influencing child well-being (Bradley, 2004), and the psychometric properties were not reported for the EHSRE Longitudinal Follow-Up study (Love et al., 2011). Concurrent and predictive validity of the measure have been established by several investigators that have found strong relations between HOME scores and children's intelligence and school readiness (Bracken, Howell, \& Crain, 1993; ChazanCohen et al., 2009).

\section{A NALYTICAL PLAN}

To address the current research questions, we used the following statistical analysis techniques. First, General Linear Model (GLM) analyses were conducted to examine whether there were differences in children's school readiness scores based on their disability indicator groups established before age 3 after controlling for relevant covariates. Posthoc multiple comparison tests were carried out following GLM analyses to explain relative differences in school readiness among children in the various disability indicator groups.

\section{RESULTS}

\section{PRELIMINARILY ANALYSES}

Child and family demographic variables were examined to determine whether they were associated with the disability indicator groups and children's school readiness scores. Table 1 presents the demographic characteristics by the disability indicator groups. Boys were more likely to be identified as having a disability indicator than girls. European American children were more likely to receive Part $\mathrm{C}$ services and less likely to be identified as having a developmental delay than were children of any other ethnicity. Children whose home language was English were more likely to be identified as receiving Part C services and having biological risks than those whose home language was not, whereas these same children were slightly less likely to be identified as having a developmental delay. Children who were enrolled in Head Start programs were more likely to be identified as having any disability indicator than those who were not. Children who were enrolled in formal care settings were more likely to receive Part $\mathrm{C}$ services, to be identified as having a biological risk, and less likely to be identified as having any other disability indicator compared to those who were not enrolled in formal care.

Mothers of children with both a suspected developmental delay, alone or in combination with a biological risk, had fewer years of education than those with children who received Part C services, children who had only a biological risk, or children who had none of the identified indi- 


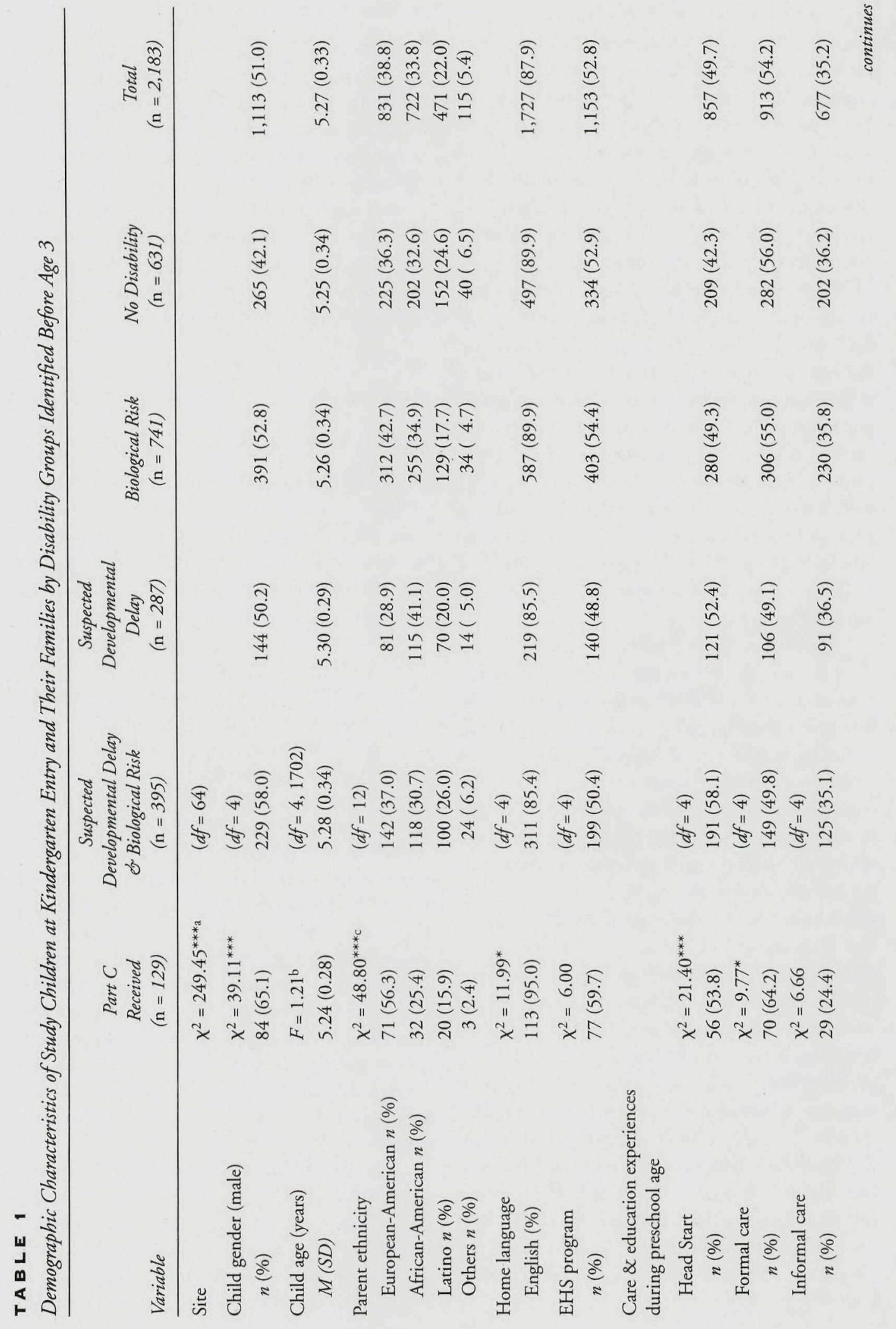




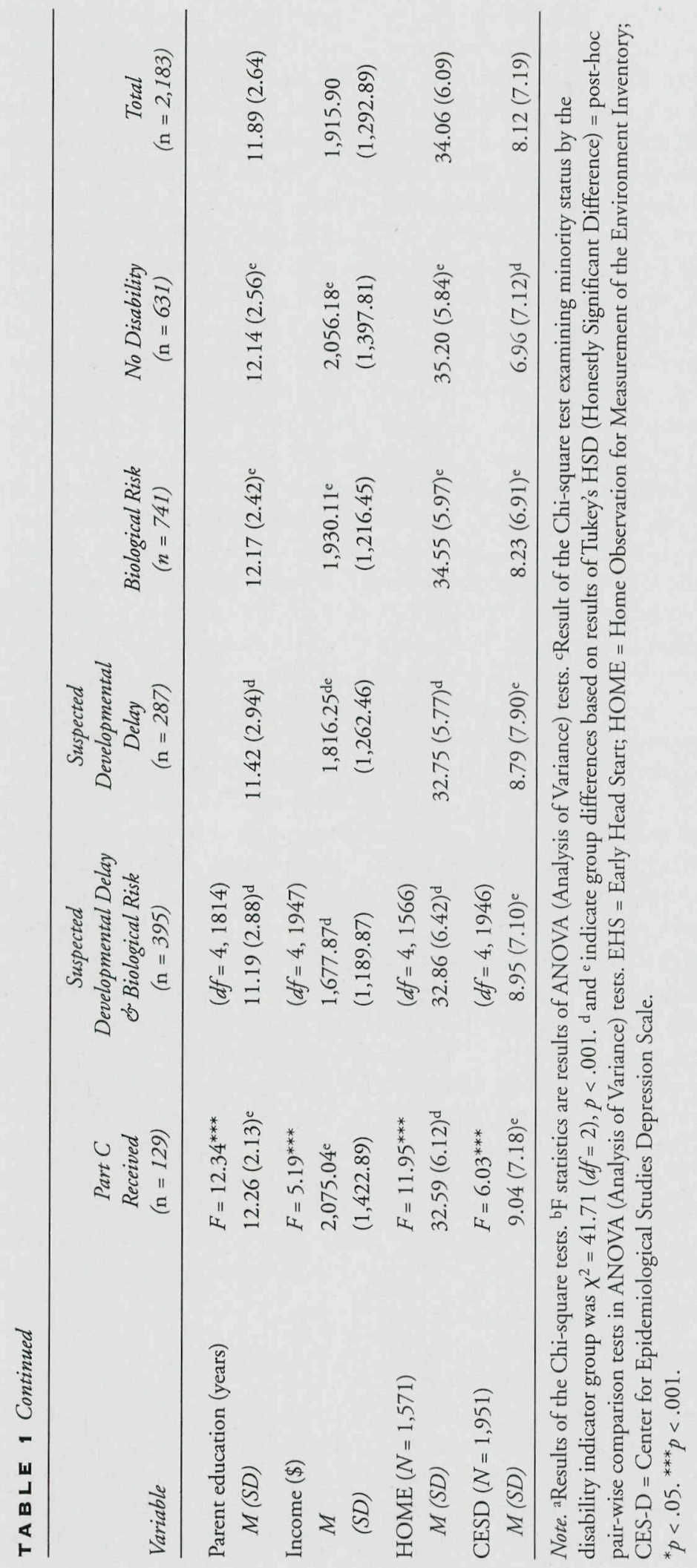


cators. Mothers of children who had any disability indicator had higher scores on the depressive symptoms scale than those of children with no identified disability indicator. Correlational analyses indicated that all these child and family demographic characteristics were also associated with children's school readiness scores. Based on results of these preliminary analyses, the following variables were selected for GLM analyses: research site, child gender, minority status, home language, Head Start and center-based child care program enrollment status, mother's symptoms of depression, mother's education, family income, and home environment. In addition, child age was added in further analyses because it was related to children's unstandardized school readiness scores (e.g., Story and Print Concepts, SSPAL, Aggressive Behavior scores). The EHS status was also included in the GLM analyses because the current study was embedded in the EHSRE randomized experimental design study. To simplify further analysis, the ethnicity variable was recoded into "minority" or "not minority" status, and public assistance variables were excluded because of their close association and overlap with family income.

GLM analyses were conducted to estimate children's school readiness using the disability indicator groups established before age 3 and receipt of Part B services. Research site, child gender, minority status, home language, EHS participation, Head Start and center-based child care program enrollment status, parent's education, family income, and home environment were all controlled in these analyses to examine differences in the estimated means on school readiness measures across the disability indicator groups.

\section{SCHOOL READINESS ESTIMATED BY}

DISABILITY INDICATORS BEFORE AGE 3 AND RECEIPT OF PART B SERVICES

Table 2 presents estimated mean scores of children's school readiness skills, after controlling for the covariates, for each of the disability indicator groups as established before age 3. According to results from this set of GLM analyses, estimated means of children's language and cognitive skills (PPVT-III, Book Comprehension, and W-J Applied Problems) varied across the different disabil- ity indicator groups. Estimated means of the emotion regulation and social skills scores (LeiterR Cognitive Social and Emotion Regulation, SSPAL, and Aggressive Behavior), however, did not differ according to disability indicator group.

Results of estimated mean pairwise comparisons show that preacademic school readiness scores (e.g., PPVT-III, Book Knowledge, and W-J Letter-Word Identification and Applied Problems) of children who received Part $\mathrm{C}$ services were not different from those of children in other disability indicator groups or from children without a disability indicator except in Book Comprehension. Further, the Book Comprehension scores of children who had received Part C services were higher than those of children who had a suspected developmental delay. The PPVT-III mean scores, however, for children identified, before age 3 , as having a suspected developmental delay, either alone or in combination with a biological risk, were significantly lower than those of children with only a biological risk or no identified disability indicator. Children who had a suspected developmental delay before age 3 had lower scores on their Book Comprehension than did those who had only a biological risk or who had no identified disability indicator. Children who had only a biological risk before age 3 had preacademic school readiness scores as high as those who did not have any identified disability indicator.

Table 3 presents the estimated means of children's school readiness scores by Part B service receipt status after controlling for the covariates. Children who received Part B services had lower scores on all preacademic skills and cognitive social and emotion regulation skills than did children who did not receive Part B services. There was no difference in SSPAL and Aggressive Behavior scores between children who received Part B services and those who did not.

\section{DISCUSSION}

The current study was a longitudinal investigation of low-income children categorized into five groups based on the presence of one or more disability indicators before age 3 . The five groups included the following: children who had received 


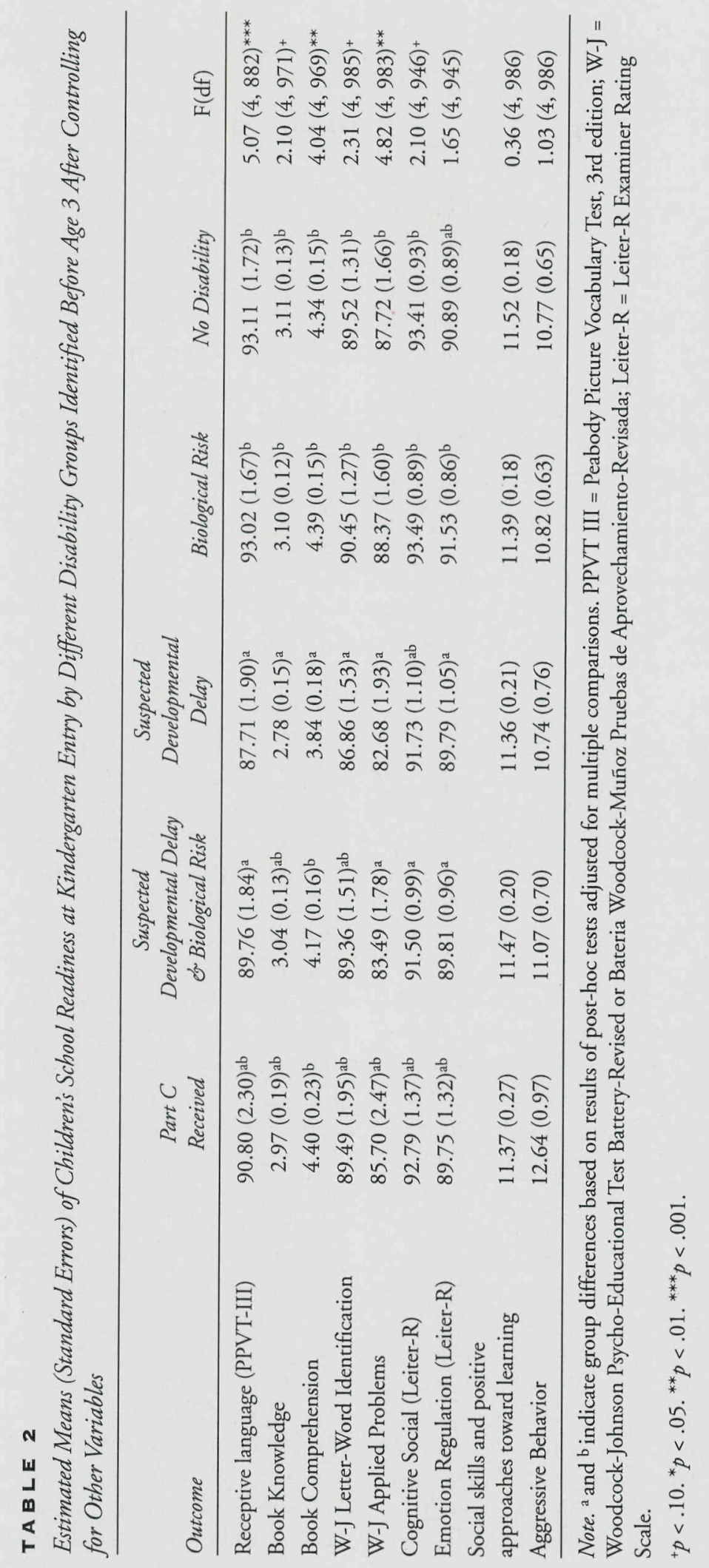


TA B LE 3

Estimated Means (Standard Errors) of Children's School Readiness at Kindergarten Entry by

Part B Service Receipt Status After Controlling for Other Variables

\begin{tabular}{lcrc}
\hline \multirow{2}{*}{ Outcome } & \multicolumn{2}{c}{ Received Part B Services } & \\
\cline { 2 - 3 } & \multicolumn{1}{c}{ No } & \multicolumn{1}{c}{ Yes } & F(df) \\
\hline Receptive language (PPVT-III) & $93.22(1.59)$ & $88.54(1.77)$ & $14.50(1,882)^{* * *}$ \\
Book Knowledge & $3.19(0.11)$ & $2.81(0.13)$ & $12.72(1,971)^{* * *}$ \\
Book Comprehension & $4.50(0.13)$ & $3.95(0.16)$ & $17.39(1,969)^{* * *}$ \\
W-J Letter-Word Identification & $90.81(1.15)$ & $86.96(1.38)$ & $11.62(1,985)^{* * *}$ \\
W-J Applied Problems & $89.63(1.46)$ & $81.55(1.75)$ & $31.71(1,983)^{* * *}$ \\
Cognitive Social (Leiter-R) & $94.92(0.81)$ & $90.26(0.98)$ & $33.04(1,946)^{* * *}$ \\
Emotion Regulation (Leiter-R) & $92.15(0.78)$ & $88.57(0.94)$ & $21.37(1,945)^{* * *}$ \\
Social skills and positive approaches & & & \\
toward learning & $11.53(0.16)$ & $11.31(0.19)$ & $2.05(1,986)$ \\
Aggressive Behavior & $10.78(0.57)$ & $11.63(0.69)$ & $2.27(1,986)$ \\
\hline
\end{tabular}

Note: PPVT III = Peabody Picture Vocabulary Test, 3rd edition; W-J = Woodcock-Johnson Psycho-Educational Test Battery-Revised or Bateria Woodcock-Muñoz: Pruebas de Aprovechamiento-Revisada; Leiter-R = Leiter-R Examiner Rating Scale.

${ }^{*} p<.05 .{ }^{* *} p<.01 .{ }^{* * *} p<.001$.

Part C services, had a suspected developmental delay, had a biological risk, had both a suspected developmental delay and a biological risk, or did not have any identified disability indicator. This study estimated school readiness for low-income children in each of these groups, as well as by their receipt of Part B services during the preschool period.

This study found no statistically significant differences in the school readiness skills between children receiving Part $\mathrm{C}$ services and children from any disability indicator groups, including those without disability indicators. This is especially notable because children who received Part $\mathrm{C}$ services may have had more serious delays than those who had a suspected developmental delay and may have had a larger gap to overcome. Few studies have examined the developmental status or school readiness of low-income children who received Part $\mathrm{C}$ services compared to those of children who did not receive Part $\mathrm{C}$ services. The only positive family outcomes of Part C services were recently found in the NEILS (Bailey et al., 2005). Generally, measuring effects of early intervention for children with disabilities is complex and challenging because children have different disability conditions and varying levels of severity; as well, children receive different types and amounts of services (Bailey, Aytch, Odom, Symons, \& Wolery, 1999). Considering that the intensity of Part $\mathrm{C}$ services seems relatively low and considerable variation exists among states in terms of coverage, eligibility criteria, and service delivery models (Bailey et al., 1999), this finding suggests that children who had a developmental delay received Part $\mathrm{C}$ services appropriate to address their developmental need areas and close gaps in school readiness relative to children who did not have a disability indicator.

At kindergarten entry, the language and cognitive scores of children who had a suspected developmental delay before age 3 were lower than those of children who had a biological risk or had no identified disability indicator. This is consistent with the results of an earlier study in which preschool children with a suspected developmental delay were found to have consistently low (more than 1.5 SD below the mean on the Battelle Development Inventory and Vineland Adaptive Behavior Scale) developmental outcome scores at 6 and 7 years of age (Shevell et al., 2005). Unlike Shevell et al., who followed only 
preschool children with a suspected developmental delay, the current study provided evidence that low-income children identified as having a suspected developmental delay early in life are more likely to have poor language and cognitive skills at school entry than are those without an identified disability indicator or those with only a biological risk. The scores of these children on standardized measures of preacademic skills, however, were still in the normal range.

Further, the current study examined the school readiness status of low-income children who were identified as having a suspected developmental delay but did not receive any Part C early intervention services, compared to those who did receive Part $\mathrm{C}$ services. The children in the current study, with a suspected developmental delay, had lower estimated mean scores than those who received Part C services after controlling for child and family characteristics and their program experiences; the differences between these two groups, however, in language and cognitive school readiness skills at kindergarten entry were not statistically significant. It is worrisome that children with a suspected developmental delay had lower school readiness skills than those who had no identified disability indicator, whereas there was little difference between the scores of children who received Part $\mathrm{C}$ services and those who did not have any identified disability indicator. Children with suspected developmental delays may benefit more from early intervention than children with other specific disability indicators. A large proportion of this sample of children was reported as having a suspected developmental delay but did not receive Part C services (Peterson et al., 2004). Rosenberg, Zhang, and Robinson (2008) found that only $10 \%$ of children who were identified as having a developmental delay at 9 months had received Part $\mathrm{C}$ services by 24 months of age. In a Canadian sample, $23 \%$ of 3 -year-old children who had a suspected developmental delay did not receive any services over a 1 -year period (Majnemer, Shevell, Rosenbaum, \& Abrahamowicz, 2002). As well, an empirical study showed that children who were identified as having a developmental delay and who received preschool special education services made significant gains in preacademic, language, and social skills (Carlson et al., 2008).
The current study found that children who had a biological risk scored as high on school readiness skills as those who had no identified disability indicator. This finding is not consistent with findings of other studies reviewed by Steen and Campbell (2008). Steen and Campbell found that studies of children with diarrhea, diabetes, very low birth weight, lead poisoning, sleep disorders, and malnutrition revealed lower cognitive abilities and a higher risk of school failure in these specific populations than in children without biological risks. The reason that the current study did not find such a difference in school readiness scores may relate to the characteristics of the sample: (a) All children in this study were living in poverty; (b) children who were identified as having a suspected developmental delay and a biological risk before age 3 were excluded from the category of children with biological risks; (c) the specific types of identified biological risks may have differed between the two studies.

About $40 \%$ of children identified as having only a biological risk before age 3 had no identified disability indicator at kindergarten entry (Peterson et al., in press). More than $29 \%$ of children who were identified as having a suspected developmental delay and a biological risk before age 3, however, received Part B services (Peterson et al., in press). These children had lower preacademic school readiness skills than did those who had only a biological risk or no disability indicator. Because this study could not answer whether certain biological risks were associated with lower preacademic school readiness skills, further longitudinal investigation is needed to understand the school readiness of children with a variety of biological risks. Several studies have found that school performance scores of children with a biological risk, in comparison to their counterparts in good health, decrease as they get older (Steen \& Campbell, 2008).

In the current study, overall, children who received Part B services had poor school readiness skills across all developmental domains (preacademic skills and cognitive social and emotion regulation skills) at kindergarten entry as compared to those who did not receive Part B services. This suggests that Part B services were provided to children who indeed needed such services. It 
will be necessary to follow these children to examine their later school performance.

More than 30\% of children who participated in the current study were identified as having a developmental delay before age 3 . It might be that because their developmental status was assessed directly at several points between birth and age 3 as part of the EHSRE study, their developmental delays were more likely to be identified. Rosenberg et al. (2008) attributed the finding that children with a developmental delay comprised up to $13 \%$ of the Early Childhood Longitudinal Study sample to the fact that they used direct child assessments instead of parent reports. The difference in percentages of children with a developmental delay between these two samples could be explained by the fact that the current sample was drawn from a low-income population. The prevalence of children with a developmental delay is higher in low-income populations $(5.0 \%)$ than in middle-class or general populations (3.8\%; Brooks-Gunn \& Duncan, 1997). The effects of poverty on children's development generally start to appear between ages 2 and 5 (Brooks-Gunn, 2003; Brooks-Gunn \& Duncan, 1997; Duncan \& Brooks-Gunn, 2000).

In this study, children's social-emotional skills at kindergarten entry did not differ by disability indicator group as established before age 3 . There is a lack of research examining social-emotional skills of children who have disability indicators, so our study represents a novel finding. The study measures used to capture children's socialemotional skills, however, were based on parent report or examiner rating completed after child direct assessments. Further investigation is necessary to confirm our findings using different measures of social-emotional-skills, such as direct observation or teacher's report.

\section{M ITATIONS}

The current research was conducted using EHSRE data. The purpose of the EHSRE study was to evaluate the long-term effects of EHS and other program experiences that children had from their birth to age 3 (Love et al., 2011), not to examine the disability indicator status of children or the effectiveness of Part $\mathrm{C}$ early intervention pro- grams. Therefore, the current study is a correlational study, and the causal relationships between children's receipt of Part C and B services and their school readiness should be interpreted cautiously. This study sample was drawn from a lowincome population eligible for EHS. The proportion of EHSRE participating children who were identified as having a developmental delay was higher than a nationally representative sample of children who had developmental delays (Scarborough et al., 2004). The findings from our study cannot be generalized to children from families of varied income levels. Moreover, in our study, children were identified as having a disability indicator based on parent and teacher reports and direct child assessments, including children identified as receiving Part $\mathrm{C}$ and $\mathrm{B}$ services. These categories are more inclusive than the eligibility criteria used by the states to identify children for these services. Thus, it is possible that children in this study were more likely to be identified as having a disability indicator than children who would be identified as eligible for Part $\mathrm{C}$ and $\mathrm{B}$ services.

\section{Future studies should follow the school performances and adjustments for children identified as having developmental risks in their early years throughout their years in school.}

The analyses in the current study did not include children's early developmental status in our prediction models because of strong stability between children's cognitive performance at ages 3 and 5. Further, children's development is not linear and can be affected by multiple factors. Future research designed to capture longitudinal trajectory patterns in developmental status and school readiness for children identified as having a developmental risk and who received Part C and B services is recommended. Future studies should follow the school performances and adjustments for children identified as having developmental risks in their early years throughout their years in school. 


\section{RECOMMENDATIONS}

These findings suggest that further studies of the developmental trajectories of children with a developmental delay who receive early intervention and early childhood special education services compared to those who do not are warranted. Longitudinal studies may provide evidence of the importance of identifying developmental delays early and tailoring programs to meet the needs of the children and their families. Further studies examining other predictors of developmental status and school readiness for children with developmental delays are necessary as well. In addition, understanding the characteristics of children who have a developmental delay and do not receive early intervention and early childhood special education services and the reasons that they do not receive these services would be helpful to improve the effective use of service systems to reach children with developmental delays and develop appropriate intervention for these children and families.

Policymakers and professionals in early intervention and early childhood special education need to focus special attention on the possibility of developmental delays among low-income children to provide appropriate services for children who do present a developmental delay. Effective strategies for screening and identifying children at risk for developmental delays may help to deliver appropriate services to these children at an early age.

\section{REFERENCES}

Achenbach, T. M., \& Rescorla, L. A. (2000). Manual for ASEBA preschool forms and profiles. Burlington, VT: University of Vermont, Research Center for Children, Youth, and Families.

Administration for Children and Families. (2002). Making a difference in the lives of infants and toddlers and their families: The impacts of early Head Start. Volume I: Final Technical Report. U.S. Department of Health and Human Services Retrieved from http:// www.acf.hhs.gov/programs/opre/ehs/ehs_resrch/ reports/impacts_vol1/impacts_vol1.pdf

Aylward, G. P. (2002). Methodological issues in outcomes studies of at-risk infants. Journal of Pediatric Psychology, 27, 37-45. doi: 10.1093/jpepsy/27.1.37
Bailey Jr, D. B., Aytch, L. S., Odom, S. L., Symons, F., \& Wolery, M. (1999). Early intervention as we know it. Mental Retardation and Developmental Disabilities Research Reviews, 5, 11-20. doi: 10.1002/(SICI) 1098-2779(1999)5:1<11::AID-MRDD2>3.0.CO;2-U

Bailey Jr., D. B., Hebbeler, K., Spiker, D., Scarborough, A., Mallik, S., \& Nelson, L. (2005). Thirty-six month outcomes for families of children who have disabilities and participated in early intervention. Pediatrics, 116, 1346-1352. doi: 10.1542/peds.2004-1239

Bracken, B. A., Howell, K. K., \& Crain, R. M. (1993). Prediction of Caucasian and African-American preschool children's fluid and crystallized intelligence: Contributions of maternal characteristics and home environment. Journal of Clinical Child Psychology, 22, 455-463. doi: 10.1207/s15374424jccp2204_6

Bracken, S. S., \& Fischel, J. E. (2008). Family reading behavior and early literacy skills in preschool children from low-income backgrounds. Early Education \& Development, 19, 45-67.

Bradley, R. H. (2004). Chaos, culture, and covariance structures: A dynamic systems view of children's experiences at home. Parenting: Science and Practice, 4, 243-257.

Brooks-Gunn, J. (2003). Do you believe in magic? What we can expect from early childhood intervention programs. Social Policy Report, 17, 1-14.

Brooks-Gunn, J., \& Duncan, G. J. (1997). The effects of poverty on children. The Future of Children, 7 , 55-71. doi: 10.2307/1602387

Brown, M. W. (1947). Goodnight moon. New York, NY: Scholastic.

Caldwell, B. M., \& Bradley, R. H. (2003). Administration manual: Home Observation for Measurement of the Environment. Little Rock, AR: University of Arkansas at Little Rock.

Carlson, E., Daley, T., Shimshak, A., Riley, J., Keller, B., Jenkins, F., \& Markowitz, J. (2008). Changes in the characteristics, services, and performance of preschoolers with disabilities from 2003-04 to 2004-05: Wave 2 overview report from the Pre-Elementary Education Longitudinal Study (U.S. Department of Education NCSER 2008-3011). Rockville, MD: Westat. Retrieved from the Pre-Elementary Education Longitudinal Study website: https://www.peels.org/Docs/ PEELS\%20Final\%20 Wave\%202\%20Overview\% 20Report.pdf

Carr, J. (2005). Stability and change in cognitive ability over the life span: A comparison of populations with and without Down's syndrome. Journal of Intellectual Disability Research, 49, 915-928. doi: 10.1111/j .1365-2788.2005.00735.x 
Chapin, L. A., \& Altenhofen, S. (2010). Neurocognitive perspectives in language outcomes of Early Head Start: Language and cognitive stimulation and maternal depression. Infant Mental Health Journal, 31, 486-498. doi: $10.1002 /$ imhj. 20268

Chazan-Cohen, R., Raikes, H., Brooks-Gunn, J., Ayoub, C., Pan, B. A., Kisker, E. E., ... Fuligni, A. S. (2009). Low-income children's school readiness: Parent contributions over the first five years. Early Education \& Development, 20, 958-977. doi: 10.1080/ 10409280903362402

Dieterich, S. E., Hebert, H. M., Landry, S. H., Swank, P. R., \& Smith, K. E. (2004). Maternal and child characteristics that influence the growth of daily living skills from infancy to school age in preterm and term infants. Early Education \& Development, 15, 283-303. doi: $10.1207 / \mathrm{s} 15566935$ eed 1503 _3

Duncan, G. J., \& Brooks-Gunn, J. (2000). Family poverty, welfare reform, and child development. Child Development, 71, 188-196. doi: 10.1111/1467-8624. 00133

Duncan, G. J., Claessens, A., Huston, A. C., Pagani, L. S., Engel, M., Sexton, H., ... Japel, C. (2007). School readiness and later achievement. Developmental Psychology, 43, 1428-1446. doi: 10.1037/0012-1649.43.6. 1428

Duncan, G. J., Yeung, W. J., Brooks-Gunn, J., \& Smith, J. R. (1998). How much does childhood poverty affect the life chances of children? American Sociological Review, 63, 406-423. doi: 10.2307/2657556

Dunn, L. M., \& Dunn, L. M. (1997). Peabody Picture Vocabulary Test 3rd Edition. Circle Pines, MN: American Guidance Service.

Entwisle, D. R., Alexander, K. L., Pallas, A. M., \& Cadigan, D. (1987). The emergent academic self-image of first graders: Its response to social structure. Child Development, 58, 1190-1206. doi: 10.2307/1130614

Fujiura, G. T., \& Yamaki, K. (2000). Trends in demography of childhood poverty and disability. Exceptional Children, 66, 187-199.

Gresham, F. M., \& Elliott, S. N. (1990). Social Skills Rating System. Circle Pines, MN: American Guidance Service.

Hammond, F. M., Hart, T., Bushnik, T., Corrigan, J. D., \& Sasser, H. (2004). Change and predictors of change in communication, cognition, and social function between 1 and 5 years after traumatic brain injury. Journal of Head Trauma Rehabilitation, 19, 314-328. doi: 10.1097/00001199-200407000-00006

Krishnakumar, A., \& Black, M. M. (2002). Longitudinal predictors of competence among African American children: The role of distal and proximal factors. Applied Developmental Psychology, 23, 237-266. doi: 10.1016/S0193-3973(02)00106-5

Ladd, G. W. (2006). Peer rejection, aggressive or withdrawn behavior, and psychological maladjustment from ages 5 to 12: An examination of four predictive models. Child Development, 77, 822-846. doi: 10.1111/j $.1467-8624.2006 .00905 . x$

Landry, S. H., Smith, K. E., \& Swank, P. R. (2006). Responsive parenting: Establishing early foundations for social, communication, and independent problemsolving skills. Developmental Psychology, 42, 627-642. doi: 10.1037/0012-1649.42.4.627-

Lee, K. (2005). Effects of experimental center-based child care on developmental outcomes of young children living in poverty. Social Service Review, 79, 158-180. doi: $10.1086 / 426721$

Lee, V. E., \& Burkam, D. T. (2002). Inequality at the starting gate: Social background differences in achievement as children begin school. Washington, DC: Economic Policy Institute.

Lomax-Bream, L. E., Taylor, H. B., Landry, S. H., Barnes, M. A., Fletcher, J. M., \& Swank, P. R. (2007). Role of early parenting and motor skills on development in children with spina bifida. Journal of Applied Developmental Psychology, 28, 250-263. doi: 10.1016/ j.appdev.2007.02.004

Love, J. M., Cohen, R. C., Raikes, H., Faldowski, R. A., Vogel, C., Klute, M., \& Kisker, E. E. (2011). What makes a difference: Analyses from the prekindergarten follow-up of the Early Head Start study. Manuscript in preparation.

Love, J. M., Harrison, L., Sagi-Schwartz, A., Ijzendoorn, M. H. V., Ross, C., Ungerer, J. A., . . ChazanCohen, R. (2003). Child care quality matters: How conclusions may vary with context. Child Development, 74, 1021-1033. doi: 0.1111/1467-8624.00584

Majnemer, A., Shevell, M. I., Rosenbaum, P., \& Abrahamowicz, M. (2002). Early rehabilitation service utilization patterns in young children with developmental delays. Child: Care, Health and Development, 28, 29-37. doi: 10.1046/j.1365-2214.2002.00237.x

Mashburn, A. J., \& Pianta, R. C. (2006). Social relationships and school readiness. Early Education \& Development, 17, 151-176. doi: 10.1207/s15566935 eed1701_7

Mason, J. M., \& Stewart, J. (1989). The CAP Early Childhood Diagnostic Instrument (Prepublication Edition). Iowa City, IA: American Testronics.

National Early Childhood Technical Assistance Center. (2007, March 8). Annual appropriations and number 
of children served under Part C of IDEA Federal fiscal years 1987-2007. Retrieved from http://www.nectac. org/partc/partcdata.asp?text $=1$

National Education Goals Panel. (1998). Ready schools. Washington, DC: U.S. Government Printing Office. Retrieved from http://govinfo.library.unt.edu/negp/ reports/readysch.pdf

National Institute of Child Health and Human Development Early Child Care Research Network. (2002). Early child care and children's development prior to school entry: Results from the NICHD Study of Early Child Care. American Educational Research Journal, 39, 133-164. doi: 10.3102/00028312039001133

Panter, J. E., \& Bracken, B. A. (2009). Validity of the Bracken School Readiness Assessment for predicting first grade readiness. Psychology in the Schools, 46, 397-409. doi: 10.1002/pits.20385

Peterson, C. A., Wall, S., Jeon, H. J., Swanson, M., Carta, J. J., Luze, G., \& Eshbaugh, E. M. (in press). Children living in poverty: Identification of disabilities and service receipt during preschool. Journal of Special Education. doi: 10.1177/0022466911407073

Peterson, C. A., Wall, S., Raikes, H. A., Kisker, E. E., Swanson, M. E., Jerald, J., ... Qiao, W. (2004). Early Head Start: Identifying and serving children with disabilities. Topics in Early Childhood Special Education, 24, 76-88. doi: 10.1177/02711214040240020301

Radloff, L. S. (1977). The CESD Scale: A self-report depression scale for research in the general population. Applied Psychological Measurement, 1, 385-401. doi: 10.1177/014662167700100306

Rimm-Kaufman, S. E., \& Pianta, R. C. (2000). An ecological perspective on the transition to kindergarten: A theoretical framework to guide empirical research. Journal of Applied Developmental Psychology, 21, 491-511. doi: 10.1016/S0193-3973(00)00051-4

Roberts, T., \& Neal, H. (2004). Relationships among preschool English language learner's oral proficiency in English, instructional experience and literacy development. Contemporary Educational Psychology, 29, 283-311. doi: 10.1016/j.cedpsych.2003.08.001

Roid, G. H., \& Miller, L. J. (1997). Examiners manual: Leiter International Performance Scale-Revised. Chicago, IL: Stoelting.

Rosenberg, S. A., Zhang, D., \& Robinson, C. C. (2008). Prevalence of developmental delays and participation in early intervention services for young children. Pediatrics, 121, 1503-1509. doi: $10.1542 /$ peds .2007-1680

Scarborough, A. A., Spiker, D., Mallik, S., \& Hebbeler, K. M. (2004). A national look at children and families entering early intervention. Exceptional Children, 70, 469-483.

Shackelford, J. (2006). State and jurisdictional eligibility definitions for infants and toddlers with disabilities under IDEA (NECTAC Notes No. 21). Chapel Hill, NC: The University of North Carolina, FPG Child Development Institute, National Early Childhood Technical Assistance Center. Retrieved from http://www. nectac.org/ - pdfs/pubs/nnotes21.pdf

Shevell, M., Majnemer, A., Platt, R. W., Webster, R., \& Birnbaum, R. (2005). Developmental and functional outcomes at school age of preschool children with global developmental delay. Journal of Child Neurology, 20, 648-654. doi: 10.1177/08830738050200080301

Snow, K. L. (2006). Measuring school readiness: Conceptual and practical considerations. Early Education \& Development, 17, 7-41. doi: 10.12071 s15566935eed1701_2

Sorongon, A., Kim, K., \& Zill, N. (n.d.). Emerging literacy. Retrieved from http://www.acf.hhs.gov/ programs/opre/hs/faces/instruments/child_instru02/ language_story.pdf

Steen, R. G., \& Campbell, F. (2008). The cognitive impact of systemic illness in childhood and adolescence. In R. G. Steen, F. Campbell, A. Prifitera, D. H. Saklofske \& L. G. Weiss (Eds.), WISC-IV Clinical Assessment and Intervention (2nd ed., pp. 365-407). San Diego, CA: Elsevier Academic Press.

Votruba-Drzal, E. (2006). Economic disparity in middle childhood development: Does income matter? Developmental Psychology, 42, 1154-1167. doi: 10.1037/ 0012-1649.42.6.1154

Woodcock, R. W., \& Johnson, M. B. (1990). Woodcock-Johnson Psycho-Educational Battery-Revised. Itasca, IL: Riverside.

Woodcock, R. W., \& Munoz-Sandoval, A. F. (1996). Bateria Woodcock-Muñoz: Pruebas de AprovechamientoRevisada. Itasca, IL: Riverside.

\section{ABOUT THE AUTHORS}

HYUN-JOO JEON (Alabama CEC), Assistant Professor, Department of Human Development and Family Studies, The University of Alabama, Tuscaloosa. CARLA A. PETERSON (Iowa CEC), Professor, Human Development and Family Studies Department, Iowa State University, Ames. Shavaun wall (District of Columbia CEC), Professor, Department of Education, The Catholic University of America, Washington, 
DC. Judith J. CARTA (Kansas CEC), Senior Scientist, Professor, Juniper Gardens Children's Project, University of Kansas, Kansas City. gayle luze (Iowa CEC), Associate Professor, Human Development and Family Studies Department, Iowa State University, Ames. ELAINE m. eshbaugh, Assistant Professor, Department of Psychology, University of Northern Iowa, Cedar Falls. MARK swanson, Centers for Disease Control and Prevention, Atlanta, Georgia.

Address correspondence concerning this article to Hyun-Joo Jeon, Box 870160, The University of Alabama, Tuscaloosa, AL 35487-0160 (e-mail: jeon@ches.ua.edu).

The findings reported here are based on research conducted as part of the national Early Head Start Research and Evaluation Project funded by the Administration for Children and Families
(ACF), U.S. Department of Health and Human Services under Contract 105-95-1936 to Mathematica Policy Research, Princeton, New Jersey, and Columbia University's Center for Children and Families, Teachers College, in conjunction with the Early Head Start Research Consortium. The Consortium consists of representatives from 17 programs participating in the evaluation, 15 local research teams, the evaluation contractors, and ACF. The content of this publication does not necessarily reflect the views or policies of the Department of Health and Human Services or the Centers for Disease Control and Prevention, nor does mention of trade names, commercial products, or organizations imply endorsement by the U.S. Government.

Manuscript received December 2009; accepted July 2010.

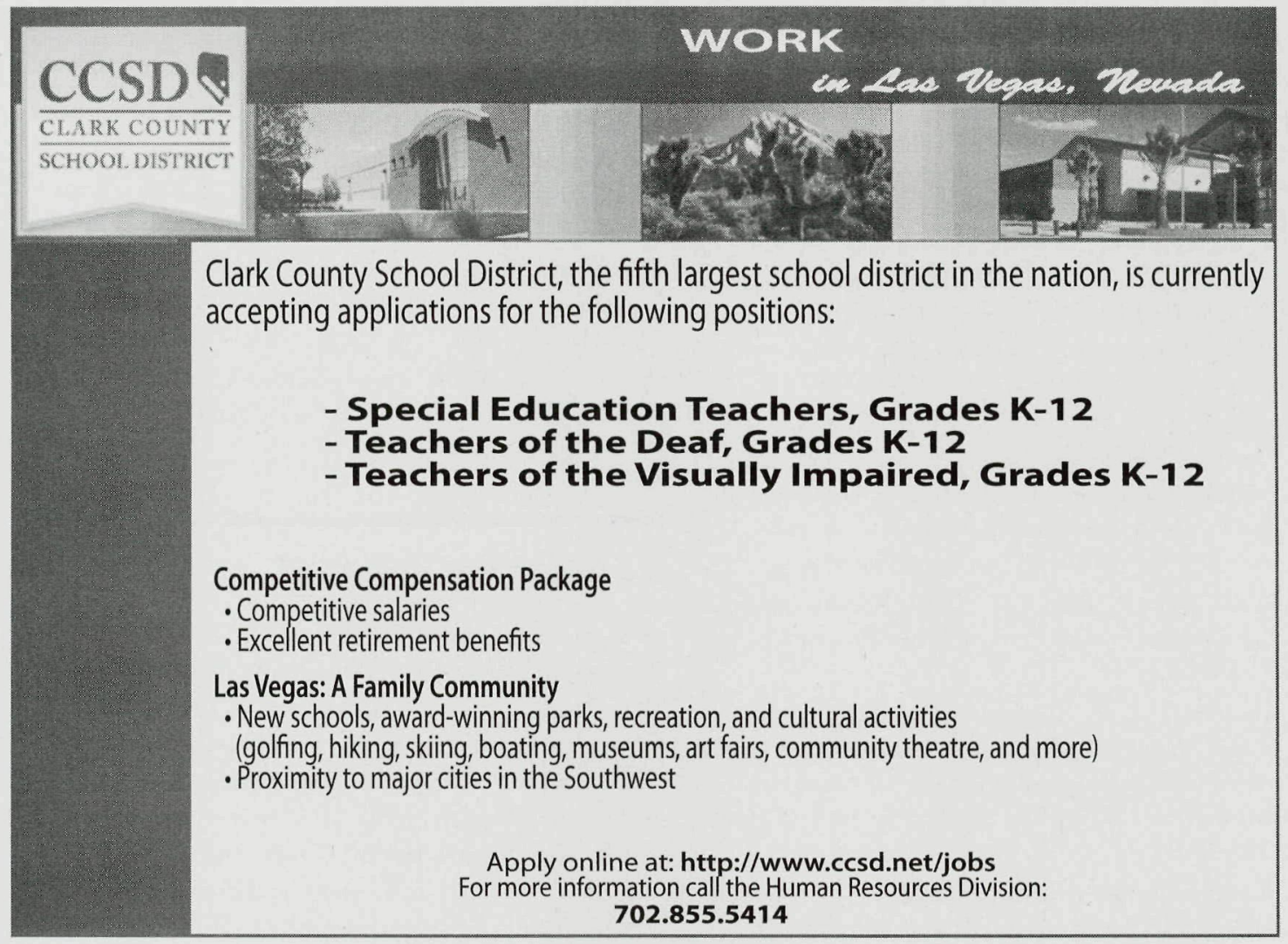


Copyright of Exceptional Children is the property of Council for Exceptional Children and its content may not be copied or emailed to multiple sites or posted to a listserv without the copyright holder's express written permission. However, users may print, download, or email articles for individual use. 